International Journal of Current Advanced Research

ISSN: O: 2319-6475, ISSN: P: 2319 - 6505, Impact Factor: SJIF: 5.995

Available Online at www.journalijcar.org

Volume 6; Issue 5; May 2017; Page No. 3731-3733

DOI: http://dx.doi.org/10.24327/ijcar.2017.3733.0358

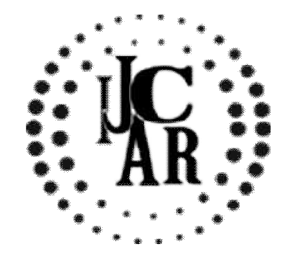

Research Article

\title{
INDIRECT SINUS LIFT - TAP TO PLACE
}

\section{Manimegalai A.G., Anand P.B and Vadivel Kumar}

Sathyabama University Dental College and Hospital A, Palace View Apartments.88/149, Santhome High road .R.A.Puram

\section{A R T I C L E I N F O}

\section{Article History:}

Received $20^{\text {th }}$ February, 2017

Received in revised form $12^{\text {th }}$ March, 2017

Accepted $15^{\text {th }}$ April, 2017

Published online $28^{\text {th }}$ May, 2017

\begin{abstract}
A B S T R A C T
Implant dentistry has become an excellent treatment modality in to the modern era Restoring the posterior maxilla with implants especially after extraction of molars presents challenges due to pneumatisation of the maxillary sinus. The procedure of choice to restore this is by maxillary sinus floor lift up. This case report presents an indirect approach for sinus lift which is less invasive and less complex and a better alternative compared to other techniques
\end{abstract}

Key words:

Indirect sinus lift, Posterior maxilla, Implants

Copyright $₫ 2017$ Manimegalai A.G et al. This is an open access article distributed under the Creative Commons Attribution License, which permits unrestricted use, distribution, and reproduction in any medium, provided the original work is properly cited.

\section{INTRODUCTION}

An essential condition for successful implant therapy is the presence of an adequate quantity and quality of bone. The posterior edentulous maxilla presents special challenges to the implant surgeon that is unique to this region compared with the other areas of the mouth. Most important among these is the presence of the maxillary sinus. The maxillary posterior edentulous area presents a challenging situation in implant dentistry when compared to other areas of the mouth. When teeth are extracted in the posterior maxilla, bone in that area is lost due to inferior expansion of the sinus involving the residual ridge area. This process is known as pneumatization of the maxillary sinus ${ }^{2}$ Moreover; bone density in this area also decreases rapidly and is the least dense area of the maxilla. When the maxillary sinus pneumatizes and no bone is available for dental implants, evaluation and treatment procedures have been developed that permit bone to be grafted into the sinus. The technique was developed by Tatum in Boyne and James was the first to publish an article and describe the technique in 1980. Implants can be placed by indirectly lifting the sinus lining when the available bone below the sinus floor is only $2-3 \mathrm{~mm}$ short of the ideal length. This procedure is called as indirect sinus lift or summers osteotome ${ }^{1}$.Implants can sometimes be placed simultaneous with the grafting procedure or it may be necessary to perform the grafting first with the implant placement being a second procedure performed several months later. When contemplating sinus grafting, it is important to know the anatomy and be able to evaluate the maxillary sinus.

*Corresponding author: Manimegalai A.G

Sathyabama University Dental College and Hospital A, Palace View Apartments.88/149, Santhome High road R.A.Puram

\section{Case Report}

A 67 year old male came to the Department of Periodontics with the chief complaint of inability to chew on the left upper back tooth region. The patient was informed about various treatment options and he expressed willingness for implant supported prosthesis for replacement. An informed consent was obtained and pre-operative assessment was carried out. On intraoral examination the patient had missing left upper premolars and $1^{\text {st }}$ and $2^{\text {nd }}$ molars. Intraoral examination the width and height of the ridge was found to be sufficient. On radiographic examination the bone height in the premolar region was found to be $8.5 \mathrm{~mm}$ and $9 \mathrm{~mm}$ in the molar region.

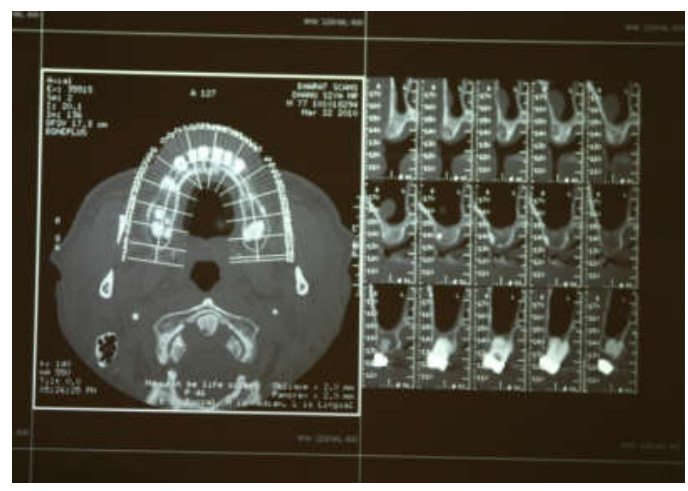

Figure $1 \mathrm{C}$ T scan of 24, 25, 26 region

The position to place the implant, position of the adjacent tooth, bone dimensions, anatomy of the maxillary sinus were considered before placement of implants. The clinical history was completed, an intraoral examination was made and intraoral and extra oral registers (study cast, frontal and lateral pictures in maximum intercuspation, excrusive movements 
and panoramic radiographs) were taken at the first visit. Radiograph showed the left maxillary sinus pneumatised with a reduced bone volume. ACT scan was done to assess to determine the accuracy of residual alveolar bone. (Figure 1)

\section{Surgical technique}

Patients rinsed $0.12 \%$ chlorhexidine for 1 minute before surgery. Under local anaesthesia a flapless approach was used to place implants. A modified Tatum technique was utilized without bone grafting material. The location of the implant was marked with a small diameter pilot drill of $1 \mathrm{~mm}$ in length working through the cortical bone. The osteotomy of the sites was carried out using a sequence of drills until the sinus floor is reached. The implant sites were prepared $1 \mathrm{~mm}$ below the sinus floor. Figure 2. A parallel pin was inserted into the surgical site and intraoperative x-ray revealed the exact length of the alveolar ridge below the sinus floor

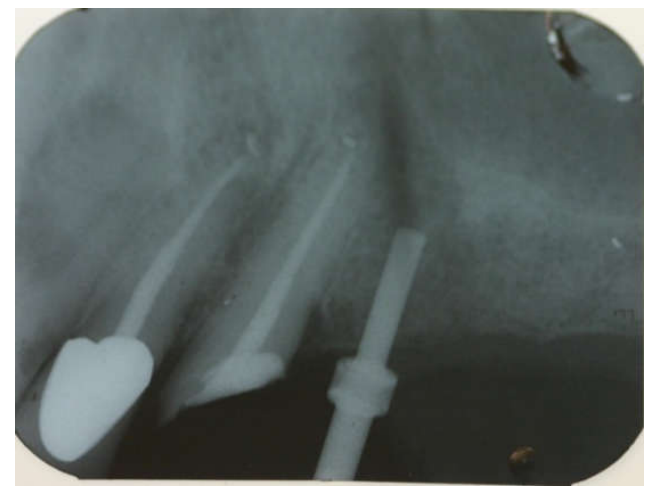

Figure 2 Implant sites preparation

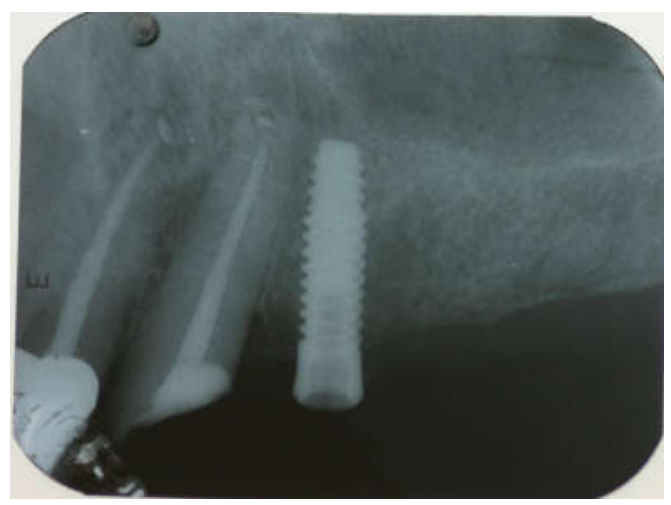

Figure 2a Placement of implant

Figure 3. A specially designed bone condenser was used to greenstick fracture and to elevate the floor with its mucosal lining attached to it to the desired level.

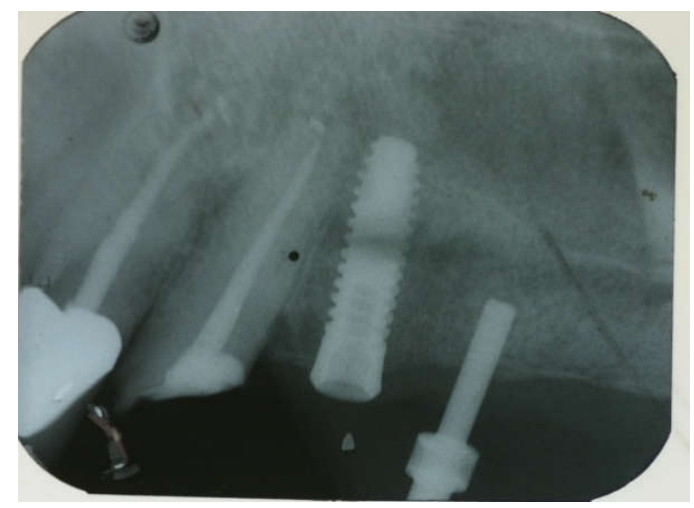

Figure 3 Insertion of parallel pin

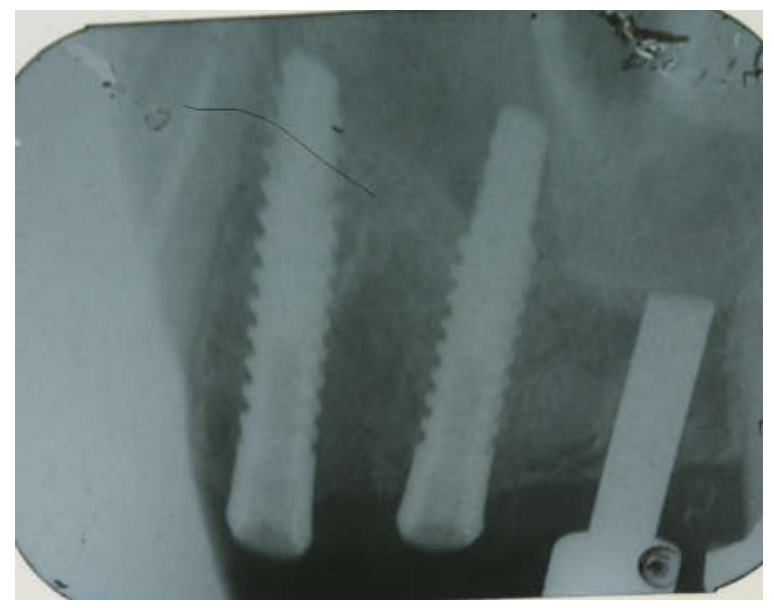

Figure 4 Placement of implants in 26 region

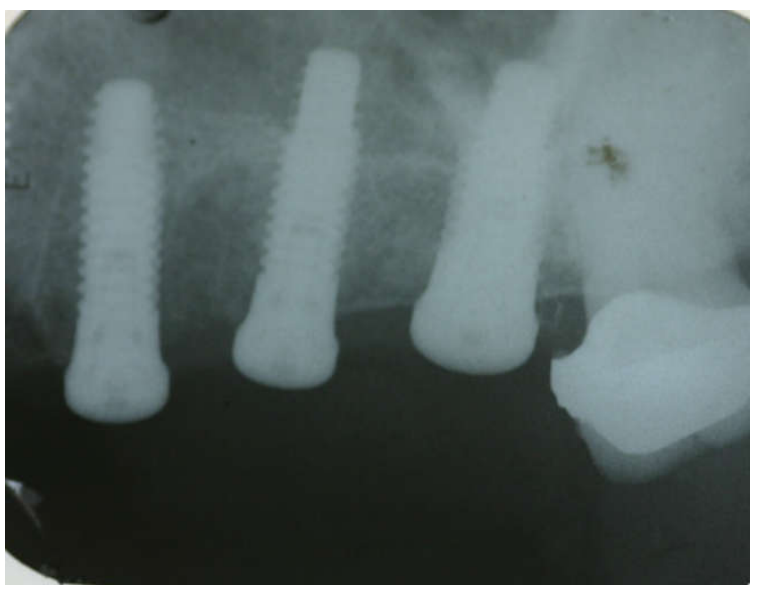

Figure 5 Implants tapped into position

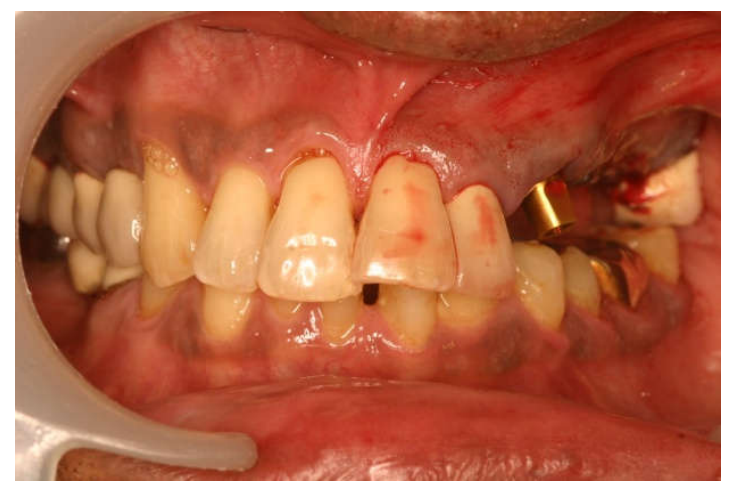

Figure 6 Post-operative view

Another x-ray was taken to check the lift and height (Figure 4). The implants were then tapped into position. Figure 5, 6 . The primary stability of implants was checked. The cover screws were then placed.

\section{DISCUSSION}

When alveolar ridges are resorbed placement of implants becomes a challenge in the maxillary posterior area. As the ridge resorbs the sinus lining comes closer to the ridge, leading to chances of sinus membrane perforation. Many techniques have been described by many authors for maxillary sinus lift $^{7}$.The sinus lift can be achieved by direct and indirect approaches. In direct approach, the sinus is approached from lateral side using one step or two step antrostomy. In indirect approach the sinus is approached from the crest of the alveolar ridge and a osteotome is used. This 
proposed technique of closed approach, is based on standardized user friendly sequence of instruments used with a controlled working action restricted to the native or residual bone ${ }^{5}$. Once the surgical working length is established, the adjustable stop device dictates the working action of manual and rotating instruments, there by minimising the risk of sinus membrane perforations. Vertical augmentation of implant site is provided by the condensed trephine bone core. When limited amount of bone is present, bone augmentation is done by additional use of graft. The combined use of trephine bur in close proximity to the sinus floor repeats the need for continuous malleting there by limiting the occurrence of BPPV (benign paroxysmal positional vertigo syndrome characterised by short recurrent episodes of vertigo 4 .

\section{References}

1. Summers RB.The osteotome technique; Less invasive methods of elevating the sinus floor (part 3).Compendium 1994; 15:698,700,702-704 passium; quiz 710 .
2. Amit agnihotari: Deepshika Agnihotri: Maxillary sinus lift up: An indirect approach for implant placement in posterior maxilla: IJOICR, MayAugust2012; 3(2):101-104.

3. A Novel sinus lift design for lateral approach. A Case report.MedOrolPatholOralCirBuccal2011 Jan 1:16(1); 79-82.

4. Trombelli.Minimal invasive technique for Transcrestal sinus floor elevation; $A$ case Report Periodontal 2010; 81; 158-166.

5. Fugazzotta PA: Immediate implant placement following a modified trephine/oste0tome approach: success rate of 115 implants to 4 years in function.Int Journal of oral and maxillofac implant, 2002; 17:557-566.

6. Emad Mohmoud Agamy Indirect Sinus Floor Elevation for Osseointegrated Prostheses.A 10 -Year Prospective Study. Journal Of Oral Implantology 2010; 15:113-121.

7. Management of the posterior maxilla with Sinus Lift: Review of Techniques., J Oral Maxillofac surg 67; 1730-1734, 2009

\section{How to cite this article:}

Manimegalai A.G et al (2017) 'Indirect Sinus Lift - Tap To Place', International Journal of Current Advanced Research, 06(05), pp. 3731-3733.DOI: http://dx.doi.org/10.24327/ijcar.2017.3733.0358 